\title{
EVALUATION OF NUTRITIONAL AND MEDICINAL PROPERTIES OF BACOPA MONNIERI BIOMASS AND PREPARATIONS
}

\author{
BOŻENA MUSZYŃSKA ${ }^{2 *}$, AGATA KRAKOWSKA ${ }^{2}$, JAN LAZUR ${ }^{1}$, \\ AGNIESZKA SZEWCZYK ${ }^{1}$ and WŁODZIMIERZ OPOKA ${ }^{2}$
}

\author{
'Department of Pharmaceutical Botany, Faculty of Pharmacy, Jagiellonian University, \\ Medical College, Kraków, Poland \\ ${ }^{2}$ Department of Inorganic and Analytical Chemistry, Faculty of Pharmacy, \\ Jagiellonian University, Medical College, Kraków, Poland
}

\begin{abstract}
Bacopa monnieri (Scrophulariaceae) is a well-known plant and has been used by humans for several thousand years. In traditional Hindu medicine, it is one of the most important medicinal plants. The aim of the work was to determine the content of $\mathrm{Fe}, \mathrm{Mg}$, and $\mathrm{Zn}$ and selected organic compounds before and after extraction into the artificial digestive juices obtained from preparations containing B. monnieri. Commercial preparations in the form of tablets and capsules and B. monnieri shoot cultures were used in the experiment. The metal content in the considered mineralized samples was analyzed by atomic absorption spectrometry and organic compounds by RP-HPLC method. The maximum measured content of the metals released into the digestive juices was as follows: $\mathrm{Fe}-32.85$; $\mathrm{Mg}-367.51$; and $\mathrm{Zn}-16.41 \mathrm{mg} / 100 \mathrm{~g}$ of the preparation. The existing research shows that metals are best released into the artificial digestive juices from the $B$. monnieri shoot cultures, and least efficiently from the commercial preparations available in the form of tablets. The phenolic compounds analyzed in the methanol extracts and the extracts of the artificial digestive juices were as follows: protocatechuic acid, $p$-hydroxybenzoic acid, neochlorogenic acid, chlorogenic acid, isochlorogenic acid, caffeic acid, ferulic acid, cynaroside, trifolin, and luteolin. Bacoside A was only determined in the extracts from the B. monnieri shoot cultures. The experimental results revealed that B. monnieri distributed in the form of tablets did not break down in the artificial digestive juices during the considered time intervals.
\end{abstract}

Keywords: Bacopa monnieri, bioelements, dietary supplements, phenolic compounds, artificial digestive juices

Bacopa monnieri (L.) Pennell (Scrophulariaceae) is one of the most important plants of Hindu traditional medicine known as Ayurveda. The term Ayurveda has its roots in ancient India and is translated as "the sacred knowledge of life." Local inhabitants of India call the plant Brahmi. The name Brahmi is not accidental, because it comes from the word Brahma, which refers to one of the three main gods of Hinduism. Giving a new local name derived from one of the Hindu gods shows how valuable and important B. monnieri is for the Indians (1-7). Raw material from this plant has been used since several centuries before Christ in the treatment of various diseases (8-11). The $B$. monnieri herb was provided to ease sleep and as an anti-anxiety agent (12). Currently, the main reason for using preparations from this plant is to improve memory and concentration $(13,14)$. The mechanism of action of $B$. monnieri supporting the normalization of memory processes affects the reactions occurring in the cholinergic system, which is responsible inter alia for memory processes (15-19). Because of the beneficial effects of the preparations produced from B. monnieri on human memory, it is also used in addition to the treatment of neurodegenerative diseases such as Parkinson's disease and Alzheimer's disease. The purpose of this work was to quantitatively determine the metals ( $\mathrm{Fe}, \mathrm{Mg}$, and $\mathrm{Zn}$ ) contained in tablets and capsules made of B. monnieri and in their shoot cultures. These elements were chosen for the experiment because of their prohealth activity close to $B$. monnieri profile of activity. It was also decided to analyze the same metals after extracting preparations to obtain artificial digestive juices, to assess their suitability for the supplementation of the human body in the analyzed bioelements. Metals were determined using the atomic absorption spectrometry method (flame tech-

\footnotetext{
* Corresponding author: e-mail: muchon@poczta.fm
} 
nique) in the obtained extracts after the incubation of products containing B. monnieri in the artificial digestive juices (gastric and intestinal). In the experiment, organic compounds such as phenolic compounds with antioxidant activity and bacoside A (the main active substance of this plant), which enhances the blood flow through the brain, were determined using the high-performance liquid chromatography (RP-HPLC) method $(4,16)$. In addition, the abovementioned elements and organic compounds were determined in the methanol extracts from the B. monnieri preparations and biomass.

Furthermore, it was determined which form (capsules or tablets) of preparations made from B. monnieri after extraction into the artificial digestive juices (gastric and intestinal) and methanol released the largest amount of bioelements as well as the tested organic compounds (phenolic compounds and bacoside A).

\section{MATERIALS AND METHODS}

\section{Materials}

The study involved the use of commercial dietary supplements in the form of tablets and capsules of B. monnieri and the shoots from the in vitro cultures of this plant (Table 1). The in vitro cultures were established from the commercially available in vitro cultures of $B$. monnieri from IVPLANT (19). Representative samples of the B. monnieri in vitro cultures were deposited at the Department of Pharmaceutical Botany, Jagiellonian University Collegium Medicum, Kraków, Poland. B. monnieri shoots were identified by the Department of Pharmaceutical Botany, Pharmacy College.

\section{Reagents and standards}

Standards of organic compounds, i.e., $p$ hydroxybenzoic, ferulic, and isoferulic acids were obtained from Fluka (Chemie AG, Germany), and those of caffeic, chlorogenic, neochlorogenic, isochlorogenic, protocatechuic acid, cynaroside, trifo- lin, luteolin, and bacoside A were from SigmaAldrich (St. Louis, USA). HPLC-grade methanol, acetic acid, and acetonitrile were purchased from Merck (Darmstadt, Germany). $\mathrm{MgCl}_{2}$ was obtained from Chempur (Kraków, Poland); $\mathrm{NaCl}, \mathrm{KCl}$, and $\mathrm{NaHCO}_{3}$ were purchased from PPH Galfarm (Kraków, Poland); pepsin and bile salts were bought from BTL (Łódź, Poland); $\mathrm{CaCl}_{2}$ was purchased from Pharma Zentrale GmbH (Germany); pancreatic extract, $\mathrm{HCl}, \mathrm{KCl}$, concentrated $\mathrm{HNO}_{3}$, Suprapur ${ }^{\circledast}$, and $\mathrm{H}_{2} \mathrm{O}_{2}$ were obtained from Merck (Darmstadt, Germany); and $\mathrm{C}_{6} \mathrm{H}_{8} \mathrm{O}_{7}, \mathrm{ZnSO}_{4}, \mathrm{KHCO}_{3}$, $\mathrm{Na}_{2} \mathrm{HPO}_{4}, \mathrm{~K}_{2} \mathrm{HPO}_{4}$, and $\mathrm{NaOH}$ were bought from Polish Company of Chemistry (Gliwice, Poland). Water (four times distilled) with a conductivity of less than $1 \mu \mathrm{S} \mathrm{cm}^{-1}$ was obtained using an S2-97A2 distillation apparatus (ChemLand, Stargard Szczecin, Poland).

The Fe(III), $\mathrm{Mg}$ (II), and $\mathrm{Zn}$ (II) ion standards at the concentration of $1 \mathrm{~g} / \mathrm{L}$ were purchased at the Regional Office of Measures in Łódź, Poland.

\section{Analysis of metals in Bacopa monnieri prepara- tions}

To determine the content of metals (Fe, Mg, and $\mathrm{Zn}$ ) in the B. monnieri preparations, the samples were subjected to mineralization. For this purpose, the samples of the preparations were prepared in the amount corresponding to the daily maximum dose (Bacopa A, 3.1 g; Bacopa B, 0.8 g; Bacopa C, 1.6 g; Bacopa D, $0.5 \mathrm{~g}$; and Bacopa E, $0.5 \mathrm{~g}$ ).

The weighed samples were transferred to Teflon tubes to which $2 \mathrm{~mL}$ of hydrogen peroxide and $4 \mathrm{~mL}$ of concentrated nitric acid solution were added. The mineralization of the $B$. monnieri preparations and biomass was performed in the Magnum II microwave mineralizator, ERTEC. Mineralization was conducted for $40 \mathrm{~min}$ in three magnetron work cycles of $15 \mathrm{~min}$ at $70 \%$ power, $15 \mathrm{~min}$ at $80 \%$ power, and $10 \mathrm{~min}$ at $100 \%$ power at $290^{\circ} \mathrm{C}$. The metals in the solutions obtained after the mineralization were determined using atomic absorption spec-

Table 1. Dietary supplements containing B. monnieri, which were used to determine the solidity of metals after extraction into the artificial digestive juices.

\begin{tabular}{|c|c|c|}
\hline Preparation & Form & Expiration date \\
\hline Bacopa A & Tablets & 11.2017 \\
\hline Bacopa B & Tablets & 06.2018 \\
\hline Bacopa C & Capsules & 10.2018 \\
\hline Bacopa D & Shoot cultures & 12.2019 \\
\hline Bacopa E & Shoot cultures with the addition of magnesium sulfate & 12.2019 \\
\hline
\end{tabular}


Table 2. Fe, $\mathrm{Mg}$, and $\mathrm{Zn}$ in the selected formulations containing B. monnieri.

\begin{tabular}{|c|c|c|c|}
\hline \multirow{2}{*}{ Preparation } & \multicolumn{3}{|c|}{ Metals content in the preparations containing B. monnieri [mg/100 g \pm SD] } \\
\cline { 2 - 4 } & Fe & Mg & Zn \\
\hline Bacopa A & $1.49 \pm 0.06^{\mathrm{a}}$ & $111.72 \pm 14.00^{\mathrm{a}}$ & $0.16 \pm 0.01^{\mathrm{a}}{ }^{\mathrm{a}}$ \\
\hline Bacopa B & $13.85 \pm 1.74^{\mathrm{a} a \mathrm{~b}}$ & $49.16 \pm 6.15^{\mathrm{a}, \mathrm{b}}$ & $0.17 \pm 0.02^{\mathrm{b}}$ \\
\hline Bacopa C & $18.92 \pm 0.05^{\mathrm{a}, \mathrm{b}, \mathrm{c}}$ & $367.51 \pm 5.01^{\mathrm{a}, \mathrm{b}, \mathrm{c}}$ & $1.88 \pm 0.01^{\mathrm{a}, \mathrm{b}, \mathrm{c}}$ \\
\hline Bacopa D & $32.85 \pm 4.76^{\mathrm{a}, \mathrm{b}, \mathrm{c}}$ & $155.08 \pm 30.91^{\mathrm{a}, \mathrm{b}, \mathrm{c}, \mathrm{d}}$ & $1.96 \pm 0.63^{\mathrm{a}, \mathrm{b}, \mathrm{d}}$ \\
\hline Bacopa E & $31.73 \pm 2.25^{\mathrm{a}, \mathrm{b}, \mathrm{c}}$ & $282.87 \pm 14.12^{\mathrm{a}, \mathrm{b}, \mathrm{c}, \mathrm{d}}$ & $16.41 \pm 0.11^{\mathrm{a}, \mathrm{c}, \mathrm{d}}$ \\
\hline \multicolumn{2}{|c|}{ Parameters of method } \\
\hline Range [mg/L] & $1-6$ & $0.1-0.5$ & $1-4$ \\
\hline Precison & 0.03 & 0.04 & 0.01 \\
\hline Repeatability [\%] & 93.21 & 96.36 & 94.50 \\
\hline
\end{tabular}

Data are presented as mean $\pm \mathrm{SD}$ (standard deviation); $\mathrm{n}=3$. Tukey-Kramer test was used to reveal the differences between paired groups of phenolic compounds in rows, the same letters $(\mathrm{a}, \mathrm{b}, \mathrm{c}, \mathrm{d})$ are marked for the content whose differences are statistically significant (for $\mathrm{p}$ values < 0.05) (GraphPad InStat)

trometry (flame technique) (iCE 3500 spectrometer, Thermo Scientific, UK). The solutions after mineralization were transferred to a quartz steamer and evaporated on a heating plate at $150^{\circ} \mathrm{C}$ to remove excess reagents. The residue was quantitatively transferred to a $10-\mathrm{mL}$ graduated flask using four times distilled water. The $\mathrm{Fe}, \mathrm{Mg}$, and $\mathrm{Zn}$ concentrations were determined using atomic absorption spectrometry (F-AAS method). An atomic absorption spectrometer from Thermo Scientific, Model iCE 3500 (UK), was used for all of the measurements. Each sample was analyzed in three independent replicates, and the results are presented as mean values (Table 2).

Analysis of metals and organic compounds in extracts obtained from preparations and cultures of Bacopa monnieri

Artificial digestive juices were prepared according to the methodology previously presented by Rojowski et al. 2017 (20).

Extracts from the preparations from $B$. monnieri used for the studies of the release of metals, phenolic compounds, and bacosides into the artificial digestive juices (20-22) were obtained as a result of the in vitro digestion process performed in the Gastroel-2014 prototype apparatus and the methanol extraction in the percolator $(19,23)$. We weighed $0.5 \mathrm{~g}$ of the shoots from the shoot cultures and a certain amount of the preparations (tablets and capsules) corresponding to the maximum daily dose recommended for the studied supplements containing B. monnieri. The weighed material was transferred to $100-\mathrm{mL}$ Erlenmeyer flasks, moistened with a 2-mL solution of artificial saliva; then, $20 \mathrm{~mL}$ of gastric juice was added into the flasks. The closed flasks were placed in the Gastroel-2014 apparatus, in which the digestive process was conducted. The process was performed for 30 and $60 \mathrm{~min}$, respectively. The obtained extracts were filtered using paper filters and membrane syringe filters. The collected filtrates were used to analyze the concentrations of metals and phenolic compounds. The remaining material was re-transferred to Erlenmeyer flasks, and $20 \mathrm{~mL}$ of intestinal juice was added. The digestion process was conducted for $150 \mathrm{~min}$. After $150 \mathrm{~min}$, the contents were re-filtered to obtain a clear solution in which, analogically to the digestion in the gastric juice, the content of metals and organic compounds was examined.

\section{Bacopa monnieri methanolic extracts preparation}

The powdered shoots $(0.5 \mathrm{~g})$ from the in vitro shoot cultures of $B$. monnieri and the same amounts of the preparations (tablets and capsules) were subjected to extraction with methanol (10 portions of $100 \mathrm{~mL}$ ) in a percolator. The methanolic extract was left at room temperature to dry. The residue was quantitatively dissolved in methanol, filtered through Millipore Millex-GP, $0.22 \mu \mathrm{m}$, and was subjected to an RP-HPLC analysis.

\section{RP-HPLC analysis of organic compounds}

The biomass and preparation extracts containing B. monnieri obtained by extraction with the digestive juices and methanol were analyzed for the content of phenolic compounds by using the RPHPLC method using a Merck-Hitachi liquid chromatograph (LaChrom Elite) equipped with a DAD detector L-2455 and a Purospher® RP-18e (250 mm 
$\times 4 \mathrm{~mm} / 5 \mathrm{~mm}$ ) column. These analyses were conducted according to the methodology developed by Sułkowska-Ziaja (24). The analyses were performed at $25^{\circ} \mathrm{C}$, with a mobile phase consisting of $\mathrm{A}$ : methanol and B: methanol: $0.5 \%$ acetic acid, $1: 4$ (v/v). The gradient was as follows: $100 \%$ B for $0-20$ min, $100 \%-80 \%$ B for $20-35 \mathrm{~min}, 80 \%-60 \%$ B for 35-55 $\mathrm{min}, 60 \%-0 \% \mathrm{~B}$ for $55-70 \mathrm{~min}, 0 \% \mathrm{~B}$ for 70-75 min, 0\%-100\% B for 75-80 min, and $100 \%$ $\mathrm{B}$ for $80-90 \mathrm{~min}$ at a flow rate $1 \mathrm{~mL} / \mathrm{min}$ at $\lambda=254$ $\mathrm{nm}$ (phenolic acids and catechins) and $\lambda=370 \mathrm{~nm}$ (flavonoids). The phenolic compounds were quantified by measuring the peak area with reference to the standard curve derived from five concentrations (0.03-0.50 mg/mL).

Similar to the analysis of phenolic compounds, extracts from the biomass and from preparations containing $B$. monnieri obtained as a result of extraction with digestive juices and methanol were analyzed for the content of bacosides by using the RPHPLC method. The RP-HPLC analyses were conducted according to the method described elsewhere (25). Analyses were performed at $25^{\circ} \mathrm{C}$, with a mobile phase consisting of A: acetonitrile, B: acetonitrile: $0.5 \%$ phosphoric acid $(0.01 \mathrm{~mol} / \mathrm{L}) 35: 65$ (v/v); gradient elution: A $(0: 100 \%), \mathrm{B}(100 \%: 0)$ at a flow rate of $1 \mathrm{~mL} / \mathrm{min}, \lambda=205 \mathrm{~nm}$. Quantification was performed by the measurement of the peak area with reference to the standard of bacoside A (bacoside A3, bacopaside II, bacopaside $\mathrm{X}$, and bacopasaponin $\mathrm{C}$ ) curve derived from five concentrations $(0.1875$ to $3 \mathrm{mg} / \mathrm{mL})$. A quantitative analysis of the organic compounds was performed using a calibration curve assuming the linear size of the area under the peak and the concentration of the reference standard. The results were expressed in milligrams per 100 grams of dry weight (d.w.).

\section{Statistical analysis}

The statistical analysis of the data was performed using one-way ANOVA with the TukeyKramer post-hoc multiple-comparison test. The value $\mathrm{p}<0.05$ was accepted as the level of statistical significance.

\section{RESULTS AND DISCUSSION}

The F-AAS method, which is characterized by high sensitivity, repeatability, and precision, was used to determine the concentration of $\mathrm{Zn}, \mathrm{Mg}$, and $\mathrm{Fe}$ in the preparations containing B. monnieri (powdered shoots, tablets, and capsules) and its extracts converted into the artificial digestive juices and methanol. The considered conditions and optimization of the analytical method allowed for an effective determination of the abovementioned elements in the tested preparations and extracts.

The $\mathrm{Zn}$ content in the tested preparations ranged from $0.16 \mathrm{mg} / 100 \mathrm{~g}$ of the preparation to $16.41 \mathrm{mg} / 100 \mathrm{~g}$ of the preparation. The highest content of $\mathrm{Zn}$ was determined in the biomass obtained from the in vitro cultures enriched with the addition of $\mathrm{MgSO}_{4}$ (16.41 mg/100 $\mathrm{g}$ of the preparation). However, the smallest content of this element was determined in a commercial preparation available in the form of compressed tablets: $0.16 \mathrm{mg} / 100 \mathrm{~g}$ of the preparation (Table 2).

In the case of the preparations in the form of tablets, very similar amounts were determined: 0.16 and $0.17 \mathrm{mg} / 100 \mathrm{~g}$ of the preparation.

To estimate the actual amounts of this element available to the human body, extraction was performed into the artificial digestive juices (using the Gastroel-2014 apparatus). Extraction was conducted under conditions imitating those prevailing in the
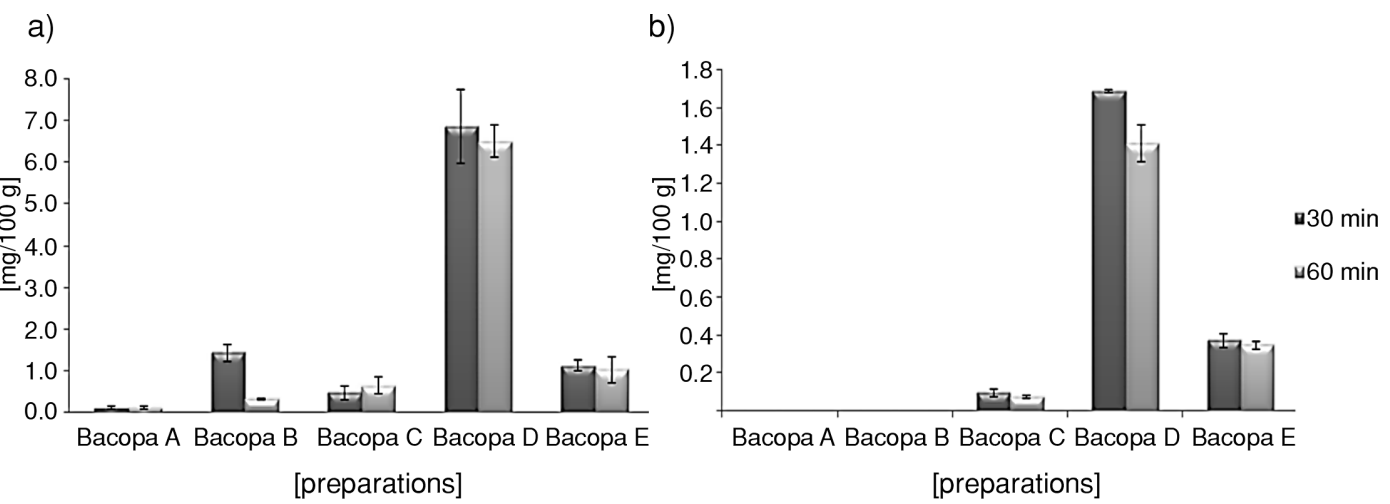

Figure 1. Zinc content (milligrams per $100 \mathrm{~g}$ of the preparation) after extraction into a) gastric juice after 30 and $60 \mathrm{~min}$, and b) intestinal juice after 30 and $60 \mathrm{~min}$ of incubation in gastric juice 

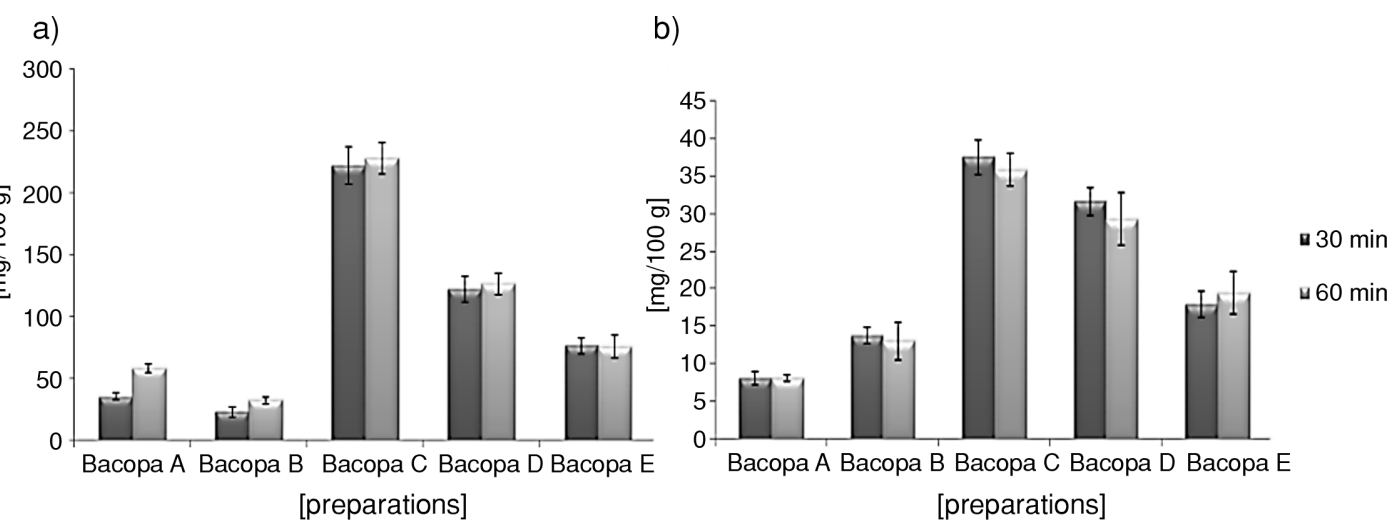

Figure 2. Magnesium content (milligrams per $100 \mathrm{~g}$ of the preparation) after extraction into a) gastric juice after 30 and $60 \mathrm{~min}$, and b) intestinal juice after 30 and $60 \mathrm{~min}$ of incubation in gastric juice

a)

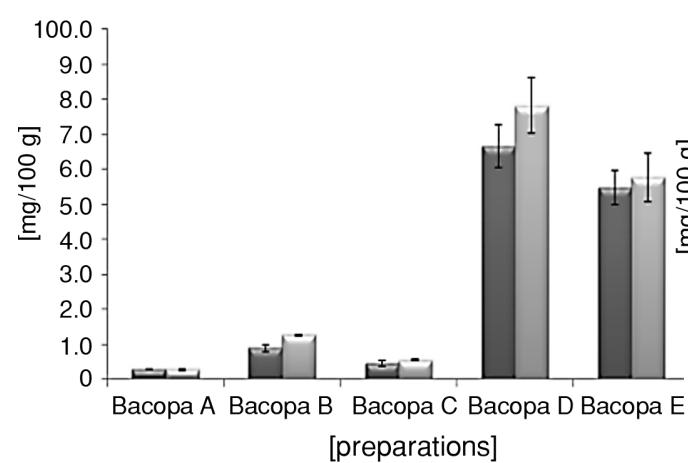

b)

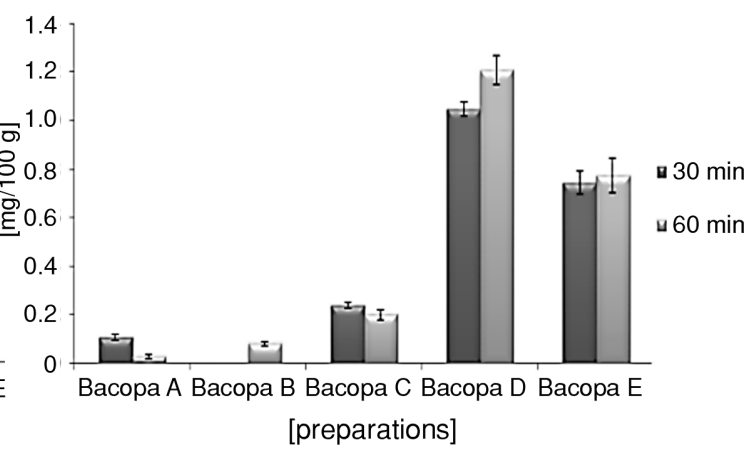

Figure 3. Iron content (milligrams per $100 \mathrm{~g}$ of the preparation) after extraction into a) gastric juice after 30 and $60 \mathrm{~min}$, and b) intestinal juice after 30 and $60 \mathrm{~min}$ of incubation in gastric juice

human body (temperature $37^{\circ} \mathrm{C}$ and movements imitating peristalsis in the human gastrointestinal tract). Based on the AAS method used for extraction into the artificial digestive juices, $\mathrm{Zn}$ was found to have been better extracted from the biomass from the in vitro shoot cultures than from the commercial preparations in the form of tablets or capsules. The quantities of $\mathrm{Zn}$ released into the artificial digestive juices were in the range of 0.07 to $6.86 \mathrm{mg} / 100 \mathrm{~g}$ of the preparation (Figs. 1a and b). The largest amount of zinc determined in the artificial gastric juice was in the range of 0.10 to $6.86 \mathrm{mg} / 100 \mathrm{~g}$ of the preparation, after $30 \mathrm{~min}$ of incubation. In contrast, in the artificial intestinal juice, these quantities were significantly lower, irrespective of the incubation time. In the case of formulations $\mathrm{A}$ and $\mathrm{B}$, no extraction into the intestinal juice was observed, whereas for preparations $\mathrm{C}, \mathrm{D}$, and $\mathrm{E}$, the amounts determined ranged from 0.07 to $1.41 \mathrm{mg} / 100 \mathrm{~g}$ of the preparation. The largest amount was released into the gastric juice after $30 \mathrm{~min}$ of incubation (Figs. 1a and b) from preparation E, i.e., from the in vitro culture biomass, and was $6.86 \mathrm{mg} / 100 \mathrm{~g}$ of the preparation. Zinc was released more efficiently from the preparations containing B. monnieri in capsules than from the commercial preparations in the form of tablets. From the results obtained for the magnesium analysis, we found that the content of this element in the preparations ranged from $49.16 \mathrm{mg} / 100 \mathrm{~g}$ of the preparation to $367.51 \mathrm{mg} / 100 \mathrm{~g}$ of the preparation. This element was released into the artificial digestive juices in amounts ranging from $22.92 \mathrm{mg} / 100 \mathrm{~g}$ 
Table 3. Content of phenolic compounds released into the artificial digestive juices from the analyzed preparations of $B$. monnieri.

\begin{tabular}{|c|c|c|c|c|c|}
\hline Artificial juice & \multicolumn{2}{|c|}{$\begin{array}{l}\text { Artificial stomach juice } \\
\text { (mg/100 g of the preparation) }\end{array}$} & \multicolumn{2}{|c|}{$\begin{array}{l}\text { Artificial intestinal juice } \\
\text { (mg/ } 100 \mathrm{~g} \text { of the preparation) }\end{array}$} & \multirow{3}{*}{ Preparation } \\
\hline Time $[\mathrm{min}]$ & 30 & 60 & 150 & 150 & \\
\hline Preparation & \multicolumn{2}{|c|}{$\begin{array}{c}\text { (after } 1 \text { min incubation } \\
\text { in artificial saliva) }\end{array}$} & \multicolumn{2}{|c|}{$\begin{array}{l}\text { (after incubation } \\
\text { in artificial stomach juice) }\end{array}$} & \\
\hline $\begin{array}{l}\text { Extract to artificial } \\
\text { digestive juice }\end{array}$ & & & & & $\begin{array}{l}\text { Methanolic extract } \\
\text { (control) }\end{array}$ \\
\hline \multicolumn{6}{|c|}{ Protocatechuic acid } \\
\hline Bacopa A & $0.10 \pm 0.00^{a}$ & $0.10 \pm 0.01^{\mathrm{a}}$ & $0.10 \pm 0.00^{\mathrm{a}}$ & $0.13 \pm 0.00^{\mathrm{a}}$ & $0.56 \pm 0.01^{a}$ \\
\hline Bacopa B & $0.45 \pm 0.03^{\mathrm{a}, \mathrm{b}}$ & $0.43 \pm 0.01^{\mathrm{a}, \mathrm{b}}$ & $0.34 \pm 0.01^{\mathrm{a}, \mathrm{b}}$ & $0.34 \pm 0.03^{\mathrm{a}, \mathrm{b}}$ & $0.40 \pm 0.00^{\mathrm{a}, \mathrm{b}}$ \\
\hline Bacopa C & $0.40 \pm 0.03^{\mathrm{a}, \mathrm{b}}$ & $0.33 \pm 0.00^{\mathrm{a}, \mathrm{b}}$ & $0.16 \pm 0.01^{\mathrm{a}, \mathrm{b}}$ & $0.17 \pm 0.00^{\mathrm{a}, \mathrm{b}}$ & $3.00 \pm 0.01^{\mathrm{a}, \mathrm{b}}$ \\
\hline Bacopa D & - & - & - & - & - \\
\hline Bacopa E & - & - & - & - & - \\
\hline \multicolumn{6}{|c|}{$p$-Hydroxybenzoic acid } \\
\hline Bacopa A & $0.03 \pm 0.00^{\mathrm{a}}$ & $0.03 \pm 0.00^{\mathrm{a}}$ & - & - & $0.14 \pm 0.01^{a}$ \\
\hline Bacopa B & $0.10 \pm 0.00^{\mathrm{a}, \mathrm{b}}$ & $0.12 \pm 0.00^{\mathrm{a}, \mathrm{b}}$ & - & - & $0.16 \pm 0.02^{b}$ \\
\hline Bacopa C & $0.27 \pm 0.02^{\mathrm{a}, \mathrm{b}}$ & $0.22 \pm 0.02^{a, b}$ & $0.15 \pm 0.03$ & $0.16 \pm 0.02$ & $4.05 \pm 0.12^{\mathrm{a}, \mathrm{b}}$ \\
\hline Bacopa D & - & - & - & - & - \\
\hline Bacopa E & - & - & - & - & - \\
\hline \multicolumn{6}{|c|}{ Neochlorogenic acid } \\
\hline Bacopa A & - & - & - & - & - \\
\hline Bacopa B & - & - & - & - & - \\
\hline Bacopa C & - & - & - & - & - \\
\hline Bacopa D & $0.80 \pm 0.03$ & $0.96 \pm 0.07$ & - & - & $7.42 \pm 0.06$ \\
\hline Bacopa E & $1.11 \pm 0.16$ & $0.86 \pm 0.02$ & & & $6.94 \pm 0.65$ \\
\hline \multicolumn{6}{|c|}{ Chlorogenic acid } \\
\hline Bacopa A & - & - & - & - & - \\
\hline Bacopa B & - & - & - & - & - \\
\hline Bacopa C & - & - & - & - & - \\
\hline Bacopa D & $4.43 \pm 0.66$ & $5.25 \pm 0.31$ & - & - & $15.04 \pm 0.75$ \\
\hline Bacopa E & $1.96 \pm 0.08$ & $2.34 \pm 0.4$ & - & - & $73.31 \pm 0.71$ \\
\hline \multicolumn{6}{|c|}{ Isochlorogenic acid } \\
\hline Bacopa A & - & - & - & - & - \\
\hline Bacopa B & - & - & - & - & - \\
\hline Bacopa C & - & - & - & - & - \\
\hline Bacopa D & $35.88 \pm 3.51$ & $45.10 \pm 6.24$ & - & - & $181.16 \pm 1.29$ \\
\hline Bacopa E & $32.03 \pm 1.81$ & $34.49 \pm 4.20$ & - & - & $864.79 \pm 17.0$ \\
\hline \multicolumn{6}{|c|}{ Caffeic acid } \\
\hline Bacopa A & - & - & - & - & - \\
\hline Bacopa B & - & - & - & - & - \\
\hline Bacopa C & - & - & - & - & - \\
\hline Bacopa D & $2.86 \pm 0.22$ & $3.13 \pm 0.38$ & - & - & $3.50 \pm 0.03$ \\
\hline Bacopa E & $2.84 \pm 0.14$ & $2.72 \pm 0.18$ & - & - & $6.60 \pm 0.14$ \\
\hline \multicolumn{6}{|c|}{ Ferulic acid } \\
\hline Bacopa A & - & - & - & - & - \\
\hline Bacopa B & - & - & - & - & - \\
\hline
\end{tabular}


Table 3. Continue.

\begin{tabular}{|c|c|c|c|c|c|}
\hline Artificial juice & \multicolumn{2}{|c|}{$\begin{array}{c}\text { Artificial stomach juice } \\
\text { (mg/100 g of the preparation) }\end{array}$} & \multicolumn{2}{|c|}{$\begin{array}{l}\text { Artificial intestinal juice } \\
\text { (mg/ } 100 \mathrm{~g} \text { of the preparation) }\end{array}$} & \multirow{3}{*}{ Preparation } \\
\hline Time $[\mathrm{min}]$ & 30 & 60 & 150 & 150 & \\
\hline Preparation & \multicolumn{2}{|c|}{$\begin{array}{l}\text { (after } 1 \text { min incubation } \\
\text { in artificial saliva) }\end{array}$} & \multicolumn{2}{|c|}{$\begin{array}{c}\text { (after incubation } \\
\text { in artificial stomach juice) }\end{array}$} & \\
\hline $\begin{array}{l}\text { Extract to artificial } \\
\text { digestive juice }\end{array}$ & & & & & $\begin{array}{l}\text { Methanolic extract } \\
\text { (control) }\end{array}$ \\
\hline Bacopa C & - & - & - & - & - \\
\hline Bacopa D & $1.96 \pm 0.08$ & $2.7 \pm 0.03$ & - & - & $226.76 \pm 0.71$ \\
\hline Bacopa E & $2.66 \pm 0.16$ & $2.30 \pm 0.67$ & $0.30 \pm 0.03$ & $0.13 \pm 0.00$ & $109.65 \pm 1.75$ \\
\hline \multicolumn{6}{|c|}{ Isoferulic acid } \\
\hline Bacopa A & - & - & - & - & - \\
\hline Bacopa B & - & - & - & - & - \\
\hline Bacopa C & - & - & - & - & - \\
\hline Bacopa D & $5.39 \pm 0.09$ & $5.26 \pm 0.22$ & - & - & $20.58 \pm 0.35$ \\
\hline Bacopa E & $5.30 \pm 0.21$ & $5.41 \pm 0.17$ & - & - & $10.76 \pm 0.39$ \\
\hline \multicolumn{6}{|c|}{ Cynaroside } \\
\hline Bacopa A & - & - & - & - & - \\
\hline Bacopa B & - & - & - & - & - \\
\hline Bacopa C & $3.76 \pm 0.03$ & $3.82 \pm 0.08$ & $3.68 \pm 0.01$ & $3.73 \pm 0.11$ & $7.69 \pm 0.27$ \\
\hline Bacopa D & - & - & - & - & - \\
\hline Bacopa E & - & - & - & - & - \\
\hline \multicolumn{6}{|c|}{ Trifolin } \\
\hline Bacopa A & - & - & - & - & - \\
\hline Bacopa B & - & - & - & - & - \\
\hline Bacopa C & $3.62 \pm 0.74$ & $3.60 \pm 0.49$ & $0.99 \pm 0.01$ & $1.16 \pm 0.12$ & - \\
\hline Bacopa D & - & - & - & - & - \\
\hline Bacopa E & - & - & - & - & - \\
\hline \multicolumn{6}{|c|}{ Luteolin } \\
\hline Bacopa A & - & - & - & - & - \\
\hline Bacopa B & - & - & - & - & - \\
\hline Bacopa C & $0.21 \pm 0.01$ & $0.21 \pm 0.01$ & $0.17 \pm 0.00$ & $0.17 \pm 0.00$ & $2.97 \pm 0.03$ \\
\hline Bacopa D & - & - & - & - & - \\
\hline Bacopa E & - & - & - & - & - \\
\hline \multicolumn{6}{|c|}{ Bacoside A } \\
\hline Bacopa A & - & - & - & - & $29.42 \pm 1.60^{\mathrm{a}}$ \\
\hline Bacopa B & - & - & - & - & $3.81 \pm 0.31^{\mathrm{a}, \mathrm{b}}$ \\
\hline Bacopa C & - & - & - & - & $1.10 \pm 0.001^{\mathrm{a}, \mathrm{c}}$ \\
\hline Bacopa D & - & - & - & - & $91.29 \pm 0.11^{\mathrm{a}, \mathrm{b}, \mathrm{c}, \mathrm{d}}$ \\
\hline Bacopa E & - & - & - & - & $327.4 \pm 22.55^{\text {a,b,c.d. }}$ \\
\hline
\end{tabular}

Data are presented as the mean \pm standard deviation (SD); $n=3$ repetitions; Tukey-Kramer test was used to reveal the differences between paired groups of phenolic compounds in columns, the same letters (a, b, c, d) are marked for the content whose differences are statistically significant (for p values <0.05) (GraphPad InStat) 
of the preparation to $228.19 \mathrm{mg} / 100 \mathrm{~g}$ of the preparation for gastric juice and from $8.09 \mathrm{mg} / 100 \mathrm{~g}$ of the preparation to $37.59 \mathrm{mg} / 100 \mathrm{~g}$ in the intestinal juice. In the case of $\mathrm{Mg}$, the incubation time in the artificial gastric juice affected the amount of element released. Increasing the incubation time from $30 \mathrm{~min}$ to $60 \mathrm{~min}$ increased the extraction efficien$\mathrm{cy}$, for which the best result was recorded for formulation $\mathrm{C}$ in the form of capsules: $228.19 \mathrm{mg} / 100$ $\mathrm{g}$ of the preparation (Figs. 2a and b). In turn, the Fe content in the analyzed preparations ranged from $1.49 \mathrm{mg} / 100 \mathrm{~g}$ of the preparation (Bacopa A) to $32.85 \mathrm{mg} / 100 \mathrm{~g}$ of the preparation (Bacopa D). The analysis of the obtained extracts from the artificial digestive juices indicated that this element was the most effectively released into the gastric juice in the amounts ranging from $0.28 \mathrm{mg} / 100 \mathrm{~g}$ of the preparation to $7.81 \mathrm{mg} / 100 \mathrm{~g}$ of the preparation. Further, in this case, the effect of the time of incubation in the digestive juices on the amount of element released into them was demonstrated. The best results were recorded for the incubation time of 60 min for the analysis of the biomass derived from the B. monnieri (Bacopa D) shoot cultures $(5.76 \mathrm{mg} / 100$ $\mathrm{g}$ of the preparation) and shoot cultures supplemented with $\mathrm{MgSO}_{4}$ (Bacopa E) $(7.81 \mathrm{mg} / 100 \mathrm{~g}$ of the preparation). However, the smallest amount of iron was extracted into the artificial gastric juice from a commercial preparation in the tablet form (Bacopa A) $(0.28 \mathrm{mg} / 100 \mathrm{~g}$ of the preparation) (Figs. 3a and b).

The artificial digestive juices did not cause the breakdown of the $B$. monnieri tablets even after the maximum incubation time, i.e., $60 \mathrm{~min}$ in the artificial gastric juice and $150 \mathrm{~min}$ in the artificial intestinal juice. During the experiment, a gel layer preventing the penetration of liquids into the interior of the tablet and the consequent disintegration of the tablet was observed on the surface of the tablets. Thus, small amounts of metals extracted into the artificial digestive juices were found, which resulted in the lack of the possibility of supplementing their deficiencies (Fe, $\mathrm{Mg}$, and $\mathrm{Zn}$ ) in the human body by using the B. monnieri preparations in the form of tablets.

Extracts into the digestive juices obtained during the tests using the Gastroel-2014 apparatus were also subjected to a qualitative-quantitative analysis of the content of organic compounds. Thus, phenolic compounds such as protocatechuic acid, p-hydroxybenzoic acid, neochlorogenic acid, chlorogenic acid, isochlorogenic acid, caffeic acid, ferulic acid, isoferulic acid, cynaroside, trifolin, luteolin, and bacoside A were found in methanol extracts and the artificial digestive juices (Table 3 ).
The commercial B. monnieri formulations provided a source of phenolic compounds, particularly protocatechuic acid, $p$-hydroxybenzoic acid, neochlorogenic acid, and chlorogenic acid. These compounds were most effectively released into the artificial gastric juice. In addition, the effect of the extraction time into the artificial digestive juices on the amount of phenolic compounds was not observed. Based on the available literature sources, it was estimated that a daily dose of phenolic compounds delivered to a man along with the daily diet should range from 0.1 to $1.0 \mathrm{~g}$. This range is broad and determined by ingredients of the daily diet, including their quantity and diversity (consumption of fruit, vegetables, and/or tea) (26). Considering the marked amounts of phenolic compounds released from the B. monnieri preparations into the artificial digestive juices, we concluded that these formulations were a supplementary source of the daily diet in these compounds, providing them from 0.03 $\mathrm{mg} /$ day ( $p$-hydroxybenzoic acid) to $45 \mathrm{mg} /$ day (isochlorogenic acid). The presence of these phenolic compounds in the obtained extracts confirmed the antioxidant activity of the raw material and the preparations obtained from it. The presence of bacoside A was found only in the methanol extracts (for Bacopa A, B, C, D, and E material), which indicated that the aqueous extracts could not be the source of this important metabolite (3). This undermined the legitimacy of using the $B$. monnieri raw materials and extracts (i.e., aqueous extracts and oral preparations). Because of the bioavailability of bacosides, we had to use only alcohol extracts. In addition, we showed that Bacopa A present in the form of tablets (compressed lyophilisate A) did not break down during the digestion process, thus failing to meet pharmacopoeial standards required for this form of the drug (disintegration should occur within $15 \mathrm{~min})(21,27)$.

\section{CONCLUSION}

Based on the conducted studies, it was found that medicinal substances from the commercial preparations of $B$. monnieri were released into the artificial digestive juices and thus, could be components potentially available to the human body and be a valuable source of phenolic compounds that supplement their deficiency. In contrast, metals (Fe, $\mathrm{Mg}$, and $\mathrm{Zn}$ ) were released into the artificial digestive juices to a different degree, and their effectiveness depended on the form in which the given preparation from B. monnieri occurred. Most effectively, the elements were released from the biomass from 
the B. monnieri shoot cultures, and their amounts allowed us to supplement the daily demand for these bioelements. Because of the bioavailability of bacosides, only alcohol extracts of $B$. monnieri were used. The conducted experiment showed that the capsules, in comparison to tablets, met pharmacopoeial standards. We also found it necessary to use alcohol extracts from the dried raw material of B. monnieri, to deliver bacoside $\mathrm{A}$ to the human body.

\section{REFERENCES}

1. Anonymous: 2. Brahmi (Mal. Brahmi). Ayurvedic drugs and their plant sources (1994).

2. Anonymous: 1. The Ayurvedic Pharmacopoeia of India (1999).

3. Ahire M.L., Walunj P.R., Kishor P.B.K.: Acta Physiol. Plant. 35, 1943 (2013).

4. Biswas S.K.: Res. J. Med. Plant. 6, 607 (2012).

5. Calabrese C.: J. Altern. Complement. Med. 14, 707 (2008).

6. Chandrasekar S.: Cell. Mol. Neurobiol. 32, 1099 (2012).

7. Gohil K.J.: Int. J. Green Pharm. 4, 1 (2010).

8. Gudipati T.: Int. J. Pharm. Bio. Sci. 3, 664 (2012).

9. Jyoti A.: J. Ethnopharmacol. 111, 56 (2007).

10. Kalyani M.I.: J. Nat. Med. 67, 123 (2013).

11. Madhavi T.: J. Med. Sci .13, 465 (2013).

12. Jyoti A.: NeuroToxicol. 27, 457 (2006).

13. Muszyńska B., Łojewski M., Smalec A., Reczyński W., Sułkowska-Ziaja K., Opoka W.: Appl. Biochem. Biotechnol. 174, 1535b (2014).
14. Muszyńska B., Łojewski M., Rojowski J., Opoka W., Sułkowska-Ziaja K.: Psychiatr. Pol. 49, 435 (2015).

15. Peth-Nui T.: Evid. Based Compl. Altern. Med. p. 10 (2012).

16. Ramasamy S., Chin S.P., Sukumaran S.D., James M., Buckle C. et al.: https://doi.org/10. 1371/journal.pone.0126565 (2015).

17. Ravikumar S.: J. Environ Biol. 26, 383 (2005).

18. Shobana C.: Cell. Mol. Neurobiol. 32, 1099 (2012).

19. Muszyńska B., Łojewski M., Sułkowska-Ziaja K., Szewczyk A., Gdula-Argasińska J., Hałaszuk P.: Pharm. Biol. 54, 2443 (2016).

20. Rojowski J., Zając M., Muszyńska B., Opoka W.: Acta Pol. Pharm. 74, 597(2017).

21. Arvidson K., Johasson E.G.: Scand. J. Dent. Res. 93, 467 (1985).

22. Polish Pharmakopeia: PTFarm. Wydanie X, Warszawa. ISBN: 978-83-63724-47-4 (2014).

23. Opoka W., Muszyńska B., Rojowski J., Rumian J.: Poland Patent Application P 417238 (2016).

24. Sułkowska-Ziaja K., Maślanka A., Szewczyk A., Muszyńska B.: Nat. Prod. Commun. 12, 363 (2017).

25. Srivastava P., Raut H.N., Puntambekar H.M., Desai A.C.: Phytochem. Anal. 23, 502 (2012).

26. Manach C., Scalbert A., Morand C., Rémésy C., Jiménez L.: Am. J. Clin. Nutr. 79, 727 (2004).

27. Council of Europe. European Pharmacopoeia $8^{\text {th }}$ ed., Strasbourg (2013).

Received: 03.05.2018 